OPEN ACCESS

Edited by:

Miriam Capri,

Università di Bologna, Italy

Reviewed by:

Giuseppe Pasqualetti,

University of Pisa, Italy

Michele Zampieri,

Sapienza Università di Roma, Italy

*Correspondence: Linhong Yuan ylhmedu@126.com

tThese authors have contributed equally to this work.

Specialty section: This article was submitted to Endocrinology of Aging, a section of the journal Frontiers in Endocrinology

Received: 01 September 2017 Accepted: 16 February 2018

Published: 06 March 2018

Citation: Huang $X$, Dong S, Zhen J, Zhang $H$, Lin T, Zeng $Y$, Van Halm-Lutterodt $N$ and Yuan L (2018) The Role of ApoE

Polymorphism in the Relationship between Serum Steroid Hormone Levels and Cognition in Older Chinese Adults: A Cross-Sectional Study. Front. Endocrinol. 9:71. doi: 10.3389/fendo.2018.00071

\section{The Role of ApoE Polymorphism in the Relationship between Serum Steroid Hormone Levels and Cognition in Older Chinese Adults: A Cross-Sectional Study}

\author{
Xiaochen Huang ${ }^{1 \dagger}$, Shengqi Dong ${ }^{1 \dagger}$, Jie Zhen ${ }^{1}$, Huiqiang Zhang ${ }^{1}$, Tong Lin ${ }^{1}$, Yuhong Zeng ${ }^{1}$, \\ Nicholas Van Halm-Lutterodt ${ }^{2,3}$ and Linhong Yuan ${ }^{1 *}$ \\ ${ }^{1}$ School of Public Health, Capital Medical University, Beijing, China, ${ }^{2}$ Department of Neurosurgery, Beijing Tiantan Hospital, \\ Capital Medical University, Beijing, China, ${ }^{3}$ Keck Medical Center of USC, Department of Orthopaedics and Neurosurgery, \\ University of Southern California, Los Angeles, CA, United States
}

Background: Epidemiology studies have indicated an association of apolipoprotein $E$ (ApoE) genetic polymorphism and circulating steroid hormone levels with the risk of Alzheimer's disease. The established physiologic relationship between apolipoproteins and steroid hormone indicate an important role of ApoE polymorphism in impacting the relationship between serum steroid hormones and cognition in the elderly.

Study design: A total of 500 Chinese adults aged between 50 and 75 participated in this community-based cross-sectional study. Blood samples were collected in the morning for ApoE genotyping and serum parameter assessment. Cognitive performance of participants was evaluated by Montreal Cognitive Assessment test.

Results: Age, gender, educational level, smoking, and physical activity levels are factors associated with cognitive performance in this older Chinese adults. Compared to the control subjects, $\mathrm{MCl}$ subjects demonstrated higher serum total cholesterol, HDL-C, and estradiol status $(P<0.05)$. ApoE genotype difference of serum lipid profile was observed with a relatively higher mean serum triglyceride levels in ApoE2 and ApoE4 carriers $(P<0.05)$, and lower mean serum HDL-C level in ApoE4 carriers $(P<0.05)$. Memory and delayed recall ability was serum estradiol level related; and subjects with higher circulating estradiol concentration exhibited lower memory and delayed recall ability $(P<0.05)$. The association of serum estradiol and cortisol concentration with cognitive performance was ApoE genotypes dependent. Poor cognitive performance was observed in ApoE2 and ApoE4 carriers with higher serum estradiol level $(P<0.05)$. Moreover, ApoE2 and ApoE4 carriers with higher serum cortisol status demonstrated decreased language ability $(P<0.05)$. Multiple logistic regression analysis indicates that subjects with higher serum estradiol status may have an increased risk for $\mathrm{MCl}$ $[O R=2.004,95 \%$ confidence interval $(\mathrm{Cl}): 1.135,3.540 ; P=0.017]$. ApoE2 carriers with higher serum steroid levels may be potentially predisposed to an increased risk of $\mathrm{MCl}$ (OR = 3.353; 95\% Cl: 1.135, 9.907; $P=0.029)$. 
Conclusion: Cognitive outcomes in older Chinese adults are associated with serum steroid hormone status. Higher serum steroid levels in ApoE2 carriers might pose an increased risk of $\mathrm{MCl}$ in the elderly.

Keywords: apolipoprotein E, polymorphism, steroid hormone, cognition, geriatrics

\section{INTRODUCTION}

Due to the prolongation of human life expectancy and the increase of elderly population in China, the prevalence of dementia is logically expected to rise. Alzheimer's disease (AD) is the most common dementia in the elderly. Until now, the cause of AD remains entirely unclear. Increasing evidence suggests that $\mathrm{AD}$ stems from a combination of environmental and hereditary factors (1). Nevertheless, implemented efforts to identify environmental and genetic risk factors associated with $\mathrm{AD}$ have not been satisfactory. Thus, the predictor identification of cognitive decline may help to forge and test for strategies in preventing dementia (2).

Circulating steroid hormones are generated from metabolism of adrenal and gonadal steroids (3). A disorder of the hypothalamic-pituitary-adrenal (HPA) axis has been linked to cognitive decline and dementia (4-6). In vivo cortisol levels have also been proven to influence explicit memory in humans and other primates (7). However, a prolonged exposure to cortisol over a lifespan period was found to play a significant role in aging process, and potentially contributing to the pathogenesis of mild cognitive decline $(8,9)$. Interestingly, with advancement in age, sex steroid levels tend to gradually decrease and this decline in steroids may be important for the reported incidence of cognitive decline in the elderly (10-12). The protective roles of sex steroid hormone in AD have been proven by population-based epidemiology studies, also by experimental animal models $(13,14)$. Significant gender differences of $\mathrm{AD}$ exist, with women being at higher risk of $\mathrm{AD}$ than men (15). Female AD patients tend to pertain a relatively lower cerebral estrogen levels compared to age-matched cognitively normal controls $(16,17)$. The decline in estrogen status in postmenopausal women evidently predisposes to accelerated precipitation of $\mathrm{AD}$-like pathology in Alzheimer transgenic model $(18,19)$.

Both human- and animal-based studies demonstrate significant correlations between in vivo steroids and risk of AD. Currently, few studies have explored the role of in vivo steroids in affecting cognitive performance in non-demented elderly Chinese population. Additionally, conflicting results regarding the relationship between circulating steroids and dementia have been reported (20). Hence, the relationship between in vivo steroids status and cognitive performance is worth considering and complementing insights into the role of endocrine factors and their impacts in influencing the development of cognitive changes.

Gene polymorphisms have been demonstrated to enhance the MCI and AD susceptibility (21). Apolipoprotein E (ApoE) is the best documented genetic risk factor for AD; especially ApoE $\varepsilon 4$ allele has been extensively reported as a major risk factor for sporadic AD (22). Due to the fact that steroid hormone is formed from a primary source of cholesterol; physiologic relationship has been established between apolipoproteins and steroids (23). Current literature evidence indicates a possible interaction between steroid hormones and ApoE allelic types in modifying the susceptibility to $\operatorname{AD}(24,25)$. Association between ApoE genetic polymorphism and basal cortisol levels in healthy older adults have also been reported (26). Additionally, the neuroprotective effects of estrogen might be modulated by ApoE genotypes. To date, the relationship between ApoE genetic polymorphism and steroids and their combined effects on cognitive performance is seldom reported in Chinese population. Given the previously reported association between ApoE and cognitive function in the elderly (24, 25), we hypothesize that ApoE gene polymorphism might interact with steroid hormones in affecting cognitive performance in non-dementia elderly Chinese. The purpose of the present study is to explore the association between in vivo estrogen and cortisol status with cognitive function in subjects with different ApoE genotypes.

\section{MATERIALS AND METHODS}

\section{Participants}

A total of 500 participants aged 50-75 (mean age: $62.63 \pm 6.16$ years) were randomly recruited from Nanyuan Community (Beijing, China). As per our previous published documents (27), the subjects with severe diseases or conditions known to affect cognitive function (e.g., inflammatory diseases, recent history of heart or respiratory failure, chronic liver disease or renal failure, malignant tumors, a recent history of alcohol abuse, history of cerebral apoplexy, or cerebral infarction) were excluded from the study. Moreover, subjects with clinically diagnosed dementia and Parkinson's disease, long-term frequency intake of medication and antidepressants acting on central nervous system, or those using hormone therapies were also excluded. The current study was approved by the Medical Ethics Committee of Capital Medical University (no. 2012SY23) and written informed consents were obtained from all participants.

\section{Anthropometric Measurements and Sociodemographic Variables}

The anthropometric parameters measured in the present study included height and weight of each participant. Body mass indices (BMIs) were calculated as weight $(\mathrm{kg}) / \mathrm{height}(\mathrm{m})^{2}$. Selfadministered questionnaires adopted from our previous studies (28) was used for the collection of demographic characteristics including age, gender, nationality, education, lifestyle factors [e.g., living condition (living alone, yes or no), smoking (yes or no), alcohol drinking (yes or no), physical activity (never, 1-3 times/week, 4-5 times/week, everyday), reading habit 
(yes or no), and housekeeping (yes or no)], AD family history (yes or no), medical history of chronic diseases, and dietary supplements. Education level was classified into six categories (illiterate, primary school, junior high school, high school, junior college, undergraduate, and above) based on the highest level attained.

\section{Blood Measurement Measurement of Serum Parameters}

Fasting venous blood samples was collected from each subject in the morning (between 8 a.m. and 9 a.m.). Then, the blood samples were centrifuged in vacuum tubes at $480 \mathrm{~g}$ for $10 \mathrm{~min}$ at $4^{\circ} \mathrm{C}$, serum was separated within $2 \mathrm{~h}$, and then stored at $-80^{\circ} \mathrm{C}$ before further analyses. Serum parameters including glucose (Glu), triglyceride (TG), and total cholesterol (TC) were measured by an ILAB8600 clinical chemistry analyzer (Instrumentation Laboratory Lexington, WI, USA). High-density lipoprotein cholesterol (HDL-C) was determined by using a commercially available assay from Instrumentation Laboratory (Lexington, WI, USA). Low-density lipoprotein cholesterol (LDL-C) concentration was calculated according to the method described by Friedewald formula (29). All samples of each subject were analyzed within a single batch, and the interassay coefficients of variation $(\mathrm{CV})$ for all determinations were less than $5 \%$.

\section{Measurement of Serum Estrogen and Cortisol}

Serum estradiol was determined utilizing a radio-immunassay kit according to the method described previously (30). The quoted $\mathrm{CV}$ was less than $10 \%$ (kit information). A competitive electrochemiluminescence immunoassay (Elecsys Cortisol; Roche Diagnostics GmbH, Mannheim, Germany) was used for cortisol concentration measurement with a total CV less than $5 \%$.

\section{DNA Isolation and Genotyping}

DNA was extracted from $2 \mathrm{ml}$ intravenous peripheral blood (stored in $-80^{\circ} \mathrm{C}$ ) by using a Wizare genomic DNA purification kit (Promega, Madison, WI, USA). Polymerase chain reaction amplification and restricted fragment length polymorphism analysis were applied for ApoE genotyping according to the method described by Hixson (31). The specific primers used for ApoE genotyping are forward, 5'-GGC ACG GCT GTCCAA GGA-3'; reverse, 5'-GCC CCG GCC TGG TAC ACT GCC-3'. $20 \%$ of DNA samples were genotyped again by different operators for the purpose of quality control. For ApoE genotypes, subjects with the E2/E2 and E2/E3 genotypes were grouped as E2 carrier; subjects with E3/E3 were classified as E3 homozygote; and subjects with $\mathrm{E} 3 / \mathrm{E} 4$ or E4/E4 were grouped as E4 carrier.

\section{Cognitive Tests}

The cognitive assessment was performed in the morning immediately after the collection of blood sample. Global cognitive function was achieved using the Montreal Cognitive Assessment (MoCA) by recruited and well trained physicians within the community health service center. As a cognitive screening tool, MoCA test was extensively applied for early detection of MCI and $\operatorname{AD}(32,33)$, which consisted of seven cognitive domains including visual-spatial and executive ability, naming, attention, abstraction, language, delayed memory recall and orientation functions. The cutoff points used for MCI diagnosis in the present study were as follows: 13/14 for individuals with no formal education, 19/20 for individuals with 1-6 years of education, and $24 / 25$ for individuals with 7 or more years of education. This cutoffs were sensitive and efficient in the diagnosis of MCI in elderly Chinese (34).

\section{Statistical Analyses}

Data were analyzed with SPSS version 19.0 (Chicago, IL, USA). Continuous variables were presented as mean \pm SD or mean [95\% confidence interval (CI)]. Gender, smoking, alcohol drinking, and physical activity were presented as category variables. Descriptive statistics were carried out on the data to investigate differences between MCI subjects and controls. General linear model (GLM) was used to compare the means of the detected parameters between the groups. Confounding factors included in the analyses while comparing serum parameters were age, gender, BMI, physical activity, smoking, and alcohol drinking. For cognitive analysis, factors including age, gender, BMI, education, and physical activity were adjusted. Chi-square test was used for binary categorical variables difference between groups. Multiple logistic regression analysis was applied to identify the factors that affect the incidence of MCI using the stepwise variable selection method. Statistical significance was set at $P<0.05$.

\section{RESULTS}

\section{Demographic Characteristics of the Participants}

The demographic characteristics of all the participants were described in Table 1. A total of 500 adults participated in the study, while 28 subjects were excluded due to their incapability of completing the questionnaires, unsuccessful ApoE genotyping or serum parameters measurement. A total of 472 individuals were finally included in the subsequent analysis. The average BMI of the participants was $25.81 \pm 8.90$. MCI subjects were significantly older than control subjects. The mean age of control and MCI participants was $62.09 \pm 5.73$ and $63.87 \pm 6.9$ years, respectively $(P<0.01)$. After categorizing the subjects according to age, we further found that, with the increase of age, the proportion of MCI increased gradually; and the highest proportion of MCI was observed in the age of $70+$ group $(P<0.05)$ (Table A1 in Appendix). The proportion of subjects with smoking habit was higher in MCI group than observed in control group $(P<0.05)$. Furthermore, the MCI subjects had significantly less physical activity than control subjects $(P<0.01)$. They also demonstrated higher serum TC and HDL-C status than control subjects $(P<0.01)$.

\section{Serum Parameters and Cognition According to ApoE Genotype}

The ApoE genotype difference of serum parameters and cognition were compared in Table 2. Compared to ApoE3 subjects, 
TABLE 1 | Demographic characteristic of the participants.

\begin{tabular}{|c|c|c|c|c|}
\hline \multirow[t]{2}{*}{ Demographic character } & \multicolumn{2}{|c|}{ Cognition } & \multirow[t]{2}{*}{ Total $(n=472)$} & \multirow[t]{2}{*}{$P$-value } \\
\hline & Normal $(n=328)$ & $\operatorname{MCl}(n=144)$ & & \\
\hline Age (year), mean $\pm S D$ & $62.09 \pm 5.73$ & $63.87 \pm 6.9$ & $62.63 \pm 6.16$ & 0.007 \\
\hline \multicolumn{5}{|l|}{ Age distribution, $n$ (\%) (year) } \\
\hline $50-60$ & $159(48.5)$ & $56(38.9)$ & $215(36.0)$ & 0.017 \\
\hline $60-70$ & $142(43.3)$ & $64(44.4)$ & $206(50.4)$ & \\
\hline$>70$ & $27(8.2)$ & $24(16.7)$ & $51(13.6)$ & \\
\hline $\mathrm{BMI}\left(\mathrm{kg} / \mathrm{m}^{2}\right)$, mean $\pm \mathrm{SD}$ & $25.84 \pm 10.42$ & $25.73 \pm 4.17$ & $25.81 \pm 8.90$ & 0.904 \\
\hline Gender, $n(\%)$ & & & & 0.035 \\
\hline Male & $84(25.6)$ & $51(35.4)$ & $135(28.6)$ & \\
\hline Female & $244(74.3)$ & $93(64.5)$ & $337(71.4)$ & \\
\hline Education, $n(\%)$ & & & & 0.003 \\
\hline |lliterate & $20(6.1)$ & $8(5.6)$ & $28(5.9)$ & \\
\hline Primary school & $71(21.6)$ & $32(22.2)$ & $103(21.8)$ & \\
\hline Junior high school & $130(39.6)$ & $80(55.6)$ & $210(44.5)$ & \\
\hline High school & $86(26.2)$ & $23(16.0)$ & $109(23.1)$ & \\
\hline Junior college & $13(4.0)$ & $1(0.7)$ & $14(3.0)$ & \\
\hline Undergraduate and above & $8(2.4)$ & $0(0.0)$ & $8(1.7)$ & \\
\hline Smoking, $n$ (yes, \%) & $39(11.9)$ & $29(20.1)$ & $68(14.4)$ & 0.023 \\
\hline Alcohol drinking, $n$ (yes, \%) & $90(27.4)$ & $38(26.4)$ & $128(27.1)$ & 0.910 \\
\hline Physical activity, $n(\%)$ & & & & 0.003 \\
\hline Never & $20(6.1)$ & $23(16.0)$ & $43(9.1)$ & \\
\hline 1-3 times/week & $45(13.7)$ & $17(11.8)$ & $62(13.1)$ & \\
\hline 4-5 times/week & $38(11.6)$ & $8(5.6)$ & $46(9.7)$ & \\
\hline Everyday & $225(68.6)$ & $96(66.7)$ & $321(68.0)$ & \\
\hline ApoE genotype, $n(\%)$ & & & & 0.074 \\
\hline E2 & $48(14.6)$ & $31(21.5)$ & $79(16.7)$ & \\
\hline E3 & $231(70.4)$ & $87(60.4)$ & $318(67.4)$ & \\
\hline E4 & $49(14.9)$ & $26(18.1)$ & 75 (15.9) & \\
\hline \multicolumn{5}{|l|}{ Serum parameters, mean \pm SE } \\
\hline GLU (mmol/L) & $6.29 \pm 1.86$ & $6.37 \pm 1.60$ & $6.31 \pm 0.08$ & 0.682 \\
\hline $\mathrm{TC}(\mathrm{mmol} / \mathrm{L})$ & $5.19 \pm 1.13$ & $5.43 \pm 1.16$ & $5.26 \pm 0.05$ & 0.009 \\
\hline $\mathrm{TG}(\mathrm{mmol} / \mathrm{L})$ & $2.23 \pm 1.79$ & $1.89 \pm 1.12$ & $2.13 \pm 0.08$ & 0.061 \\
\hline LDL-C (mmol/L) & $3.01 \pm 0.89$ & $3.00 \pm 0.84$ & $3.01 \pm 0.04$ & 0.735 \\
\hline HDL-C (mmol/L) & $1.39 \pm 0.28$ & $1.48 \pm 0.30$ & $1.42 \pm 0.01$ & 0.000 \\
\hline Estradiol (pg/ml) & $18.86 \pm 13.92$ & $22.45 \pm 13.65$ & $19.95 \pm 0.64$ & 0.099 \\
\hline Cortisol (ng/ml) & $210.41 \pm 49.85$ & $210.69 \pm 54.95$ & $210.50 \pm 2.37$ & 0.841 \\
\hline
\end{tabular}

Chi-square test was used for binary categorical variables difference between groups. General linear model (GLM) method was used for the comparison of serum parameters. During the comparison of serum GLU, TC, TG, LDL-C, and HDL-C, confounding factors including age, sex, BMI, physical activity, smoking, and alcohol drinking were adjusted. During the comparison of serum estradiol and cortisol levels, confounding factors including age, sex, BMI, and physical activity were adjusted. P-value < 0.05 was considered as significance. BMI, body mass index; ApoE, apolipoprotein E. TC, total cholesterol; TG, triglyceride; LDL-C, low-density lipoprotein cholesterol; HDL-C, high-density lipoprotein cholesterol.

ApoE2 and ApoE4 carriers significantly demonstrated a relatively higher serum TG concentration $(P<0.01)$. Moreover, highest mean serum HDL-C level was also detected in ApoE2 carriers $(P<0.05)$. ApoE4 carriers demonstrated the lowest mean serum HDL-C levels $(P<0.05)$. They also have a lower naming ability compared to ApoE3 and ApoE2 carriers $(P<0.05)$.

\section{Association of Serum Steroid Hormone Levels with Cognition}

We categorized the participants according to the quartile of serum estrogen and cortisol levels into four groups (Q1-Q4). As shown in Table 3, subjects in the top quartile of serum estradiol (Q4) group have the lowest memory and delayed recall ability compared to the subjects in Q1 and Q2 groups $(P<0.05)$. As shown in Table 4, there was no significant difference between cognitive performances by serum cortisol status in the elderly participants $(P>0.05)$.

\section{Cognition According to Serum Steroid Hormone Levels and ApoE Genotype}

The association of serum estradiol status and cognitive performance by ApoE genotype were observed (Table 5). ApoE2 carriers with the highest serum estradiol status (Q4) have the lowest visual-spatial and executive ability $(P<0.05)$. Compared to ApoE3 and E2 subjects in Q1 group, ApoE4 carriers have the highest naming abilities, while the E4 subject in Q3 group have the lowest naming ability $(P<0.05)$. Furthermore, difference of visual-spatial and executive ability and naming ability across estradiol quartiles by ApoE genotype were also demonstrated $(P<0.05)$.

As shown in Table 6, the association of serum cortisol with language ability by ApoE genotype was detected. Language ability of ApoE2 carriers diminished accordingly with the increase of serum cortisol status; and the lowest language ability was observed in ApoE2 carriers in Q4 group $(P<0.05)$. ApoE4 carriers with Q3 
TABLE 2 | Serum parameters and cognition according to ApoE genotype.

\begin{tabular}{|c|c|c|c|c|}
\hline \multirow[t]{2}{*}{ Parameters and cognition } & \multicolumn{3}{|c|}{ ApoE genotype $(n=472)$} & \multirow[t]{2}{*}{$P$-value } \\
\hline & $\mathrm{E} 2(n=79)$ & E3 $(n=318)$ & $\mathrm{E} 4(n=75)$ & \\
\hline \multicolumn{5}{|l|}{ Parameters } \\
\hline GLU (mmol/l) & $6.03(5.62,6.45)$ & $6.41(6.21,6.61)$ & $6.22(5.81,6.64)$ & 0.415 \\
\hline $\mathrm{TC}(\mathrm{mmol} / \mathrm{l})$ & $5.34(5.08,5.60)$ & $5.24(5.12,5.36)$ & $5.27(5.02,5.53)$ & 0.802 \\
\hline $\mathrm{TG}(\mathrm{mmol} / \mathrm{l})$ & $2.69(2.31,3.07)^{\star}$ & $1.98(1.80,2.16)$ & $2.20(1.82,2.58)$ & 0.009 \\
\hline LDL-C (mmol/l) & $2.79(2.60,2.99)^{\star}$ & $3.04(2.94,3.14)$ & $3.08(2.88,3.28)$ & 0.074 \\
\hline HDL-C (mmol/l) & $1.50(1.44,1.57)^{\star}$ & $1.41(1.38,1.44)$ & $1.37(1.31,1.44)^{\star \star}$ & 0.024 \\
\hline Estradiol (pg/ml) & $20.44(17.64,23.23)$ & $20.14(18.81,21.48)$ & $18.55(15.82,21.28)$ & 0.546 \\
\hline Cortisol (ng/ml) & $206.78(194.86,218.70)$ & $212.76(207.06,218.46)$ & $204.80(193.15,216.45)$ & 0.386 \\
\hline \multicolumn{5}{|l|}{ Cognition } \\
\hline MoCA score & $22.69(21.41,23.96)$ & $23.87(23.26,24.48)$ & $22.54(21.28,23.80)$ & 0.143 \\
\hline Visual and executive & $3.38(3.08,3.67)$ & $3.69(3.55,3.83)$ & $3.45(3.16,3.74)$ & 0.190 \\
\hline Naming & $2.85(2.72,2.97)$ & $2.90(2.84,2.96)$ & $2.69(2.57,2.81)^{*}$ & 0.025 \\
\hline Attention & $5.06(4.75,5.37)$ & $5.17(5.02,5.31)$ & $4.98(4.68,5.29)$ & 0.738 \\
\hline Language & $1.91(1.71,2.11)$ & $2.12(2.03,2.22)$ & $1.94(1.74,2.13)$ & 0.101 \\
\hline Abstraction & $1.35(1.16,1.54)$ & $1.54(1.45,1.64)$ & $1.41(1.22,1.60)$ & 0.232 \\
\hline Memory and delayed recall & $2.47(2.13,2.81)$ & $2.72(2.56,2.89)$ & $2.60(2.27,2.94)$ & 0.426 \\
\hline Orientation & $5.68(5.42,5.93)$ & $5.74(5.62,5.86)$ & $5.47(5.22,5.72)$ & 0.299 \\
\hline
\end{tabular}

Data were expressed as mean (95\% Cl). General linear model (GLM) was used for data analysis. When comparing serum parameters, factors including gender, age, BMI, smoking, alcohol drinking, and physical activity were adjusted. When comparing cognition, factors including gender, age, BMI, smoking, alcohol drinking, physical activity, and education were adjusted. P-value $<0.05$ was considered as significance.

${ }^{*}$ Comparing with ApoE3 carriers, $P<0.05$.

${ }^{* *}$ Comparing with ApoE2 carriers, $P<0.05$.

GLU, glucose; TC, total cholesterol; TG, triglyceride; LDL-C, low-density lipoprotein cholesterol; HDL-C, high-density lipoprotein cholesterol; ApoE, apolipoprotein E.

TABLE 3 | Cognition according to serum estradiol level.

\begin{tabular}{|c|c|c|c|c|c|}
\hline Cognition & \multicolumn{4}{|c|}{ Estradiol $(\mu \mathrm{g} / \mathrm{ml})$} & $P$-value \\
\hline MoCA score & $23.90(22.89,24.90)$ & $23.94(22.96,24.91)$ & $22.99(22.03,23.96)$ & $22.91(21.83,23.99)$ & 0.360 \\
\hline Naming & $2.89(2.79,2.99)$ & $2.88(2.77,2.98)$ & $2.81(2.71,2.91)$ & $2.83(2.72,2.95)$ & 0.654 \\
\hline Attention & $5.20(4.94,5.45)$ & $5.12(4.88,5.37)$ & $5.02(4.78,5.26)$ & $5.10(4.83,5.37)$ & 0.790 \\
\hline Language & $2.11(1.95,2.27)$ & $2.09(1.93,2.24)$ & $2.05(1.90,2.20)$ & $1.98(1.81,2.15)$ & 0.736 \\
\hline Orientation & $5.69(5.48,5.90)$ & $5.71(5.51,5.92)$ & $5.57(5.36,5.77)$ & $5.72(5.49,5.95)$ & 0.697 \\
\hline
\end{tabular}

Data were expressed as mean (95\% Cl). General linear model (GLM) was used for data analysis. Possible confounding factors including gender, age, BMI, smoking, physical activity, and education were adjusted. $P<0.05$ was considered to be statistically significant.

${ }^{*}$ Comparing with Q1 group, $P<0.05$.

MoCA, Montreal Cognitive Assessment; $Q$, quartile.

level of serum cortisol also demonstrated diminished language ability $(P<0.05)$. Additionally, difference of language ability across cortisol quartiles by ApoE genotype was indicated in the current study $(P<0.05)$.

\section{Steroid Hormones and ApoE Genotype Affect the Occurrence of $\mathrm{MCl}$}

The association of serum steroids concentrations and ApoE genotype with the risk of MCI in the elderly was explored by using multiple logistic regression analysis after adjusting the potential confounding factors including age, BMI, gender, educational level, smoking, and physical activity level (Table 7). The MCI risk for the subjects with Q3 or Q4 quartile of serum estradiol level increased by 1.958 (95\% CI: 1.107, 3.466; $P=0.021)$ and 2.004 (95\% CI: 1.135, 3.540; $P=0.017$ ), respectively. Interaction between serum estradiol concentration and ApoE genotype in affecting the risk of MCI was also observed. ApoE2 carriers with high serum estradiol (Q4 quartile) have increased risk of MCI than ApoE3 subjects with the low quartile (Q1) of serum estradiol level $(P<0.05)$. The interaction between ApoE genotype and serum cortisol level and the risk of MCI was only observed in the subjects with top quartile (Q4) of serum cortisol status. ApoE2 carriers with Q4 quartile of serum cortisol level demonstrated a potential increase in the risk for $\mathrm{MCI}(\mathrm{OR}=3.353$; 95\% CI: 1.135 , 9.907; $P=0.029)$.

\section{DISCUSSION}

The demographic characters of the participants were compared; and the differences in age, educational level and lifestyle between 
TABLE 4 | Cognition according to serum cortisol level.

\begin{tabular}{|c|c|c|c|c|c|}
\hline \multirow[t]{2}{*}{ Cognition } & \multicolumn{4}{|c|}{ Cortisol ( $\mu \mathrm{g} / \mathrm{ml})$} & \multirow[t]{2}{*}{$P$-value } \\
\hline & Q1 $(n=118)$ & Q2 $(n=118)$ & Q3 $(n=118)$ & Q4 $(n=118)$ & \\
\hline MoCA score & $22.92(21.94,23.89)$ & $23.61(22.65,24.58)$ & $23.73(22.76,24.70)$ & $23.46(22.49,24.43)$ & 0.662 \\
\hline Visual-spatial and executive & $3.54(3.32,3.76)$ & $3.68(3.46,3.89)$ & $3.52(3.31,3.74)$ & $3.66(3.44,3.88)$ & 0.696 \\
\hline Naming & $2.87(2.77,2.97)$ & $2.83(2.73,2.93)$ & $2.83(2.73,2.93)$ & $2.88(2.78,2.99)$ & 0.826 \\
\hline Attention & $4.89(4.65,5.13)$ & $5.13(4.89,5.37)$ & $5.23(4.99,5.47)$ & $5.18(4.93,5.42)$ & 0.217 \\
\hline Language & $2.06(1.91,2.21)$ & $2.09(1.94,2.24)$ & $2.05(1.89,2.20)$ & $2.03(1.88,2.18)$ & 0.966 \\
\hline Abstraction & $1.40(1.25,1.55)$ & $1.52(1.37,1.66)$ & $1.49(1.34,1.64)$ & $1.55(1.40,1.70)$ & 0.529 \\
\hline Memory and delayed recall & $2.57(2.31,2.82)$ & $2.76(2.51,3.02)$ & $2.87(2.61,3.13)$ & $2.44(2.18,2.70)$ & 0.088 \\
\hline Orientation & $5.60(5.40,5.81)$ & $5.61(5.41,5.81)$ & $5.74(5.54,5.95)$ & $5.73(5.52,5.93)$ & 0.674 \\
\hline
\end{tabular}

Data were expressed as mean (95\% Cl). General linear model (GLM) was used for data analysis. Possible confounding factors including gender, age, BMI, smoking, physical activity, and education were adjusted. $P<0.05$ was considered to be statistically significant.

MoCA, Montreal Cognitive Assessment; Q, quartile.

TABLE 5 | Cognition according to serum estradiol level and ApoE genotype.

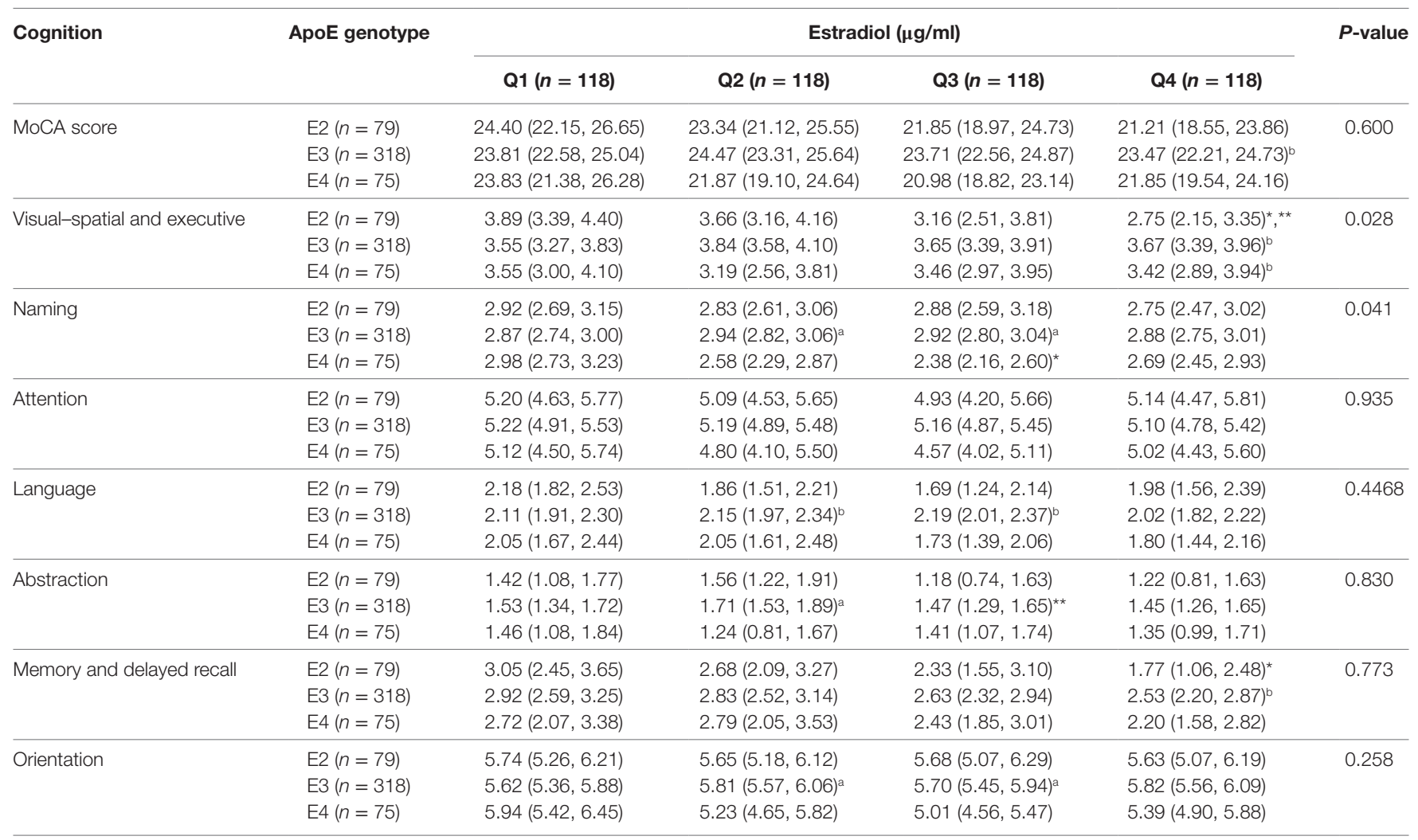

Data were expressed as mean (95\% Cl). General linear model (GLM) was used for data analysis. Possible confounding factors including gender, age, BMI, smoking, physical activity, and education were adjusted. $P<0.05$ was considered to be statistically significant.

${ }^{*}$ Comparing with $Q 1$ group, $P<0.05$.

${ }^{* *}$ Comparing with Q2 group, $P<0.05$.

${ }^{a}$ Comparing with E4 carriers, $P<0.05$.

${ }^{b}$ Comparing with E2 carriers, $P<0.05$.

ApoE, apolipoprotein E; MoCA, Montreal Cognitive Assessment; Q, quartile.

MCI and control subjects were observed. Our results were consistent with previously published studies (35-37). Comprehensively, these data demonstrate that age, educational level, physical activity, and smoking are influencing factors associated with cognitive performance in elderly Chinese. We did not observe any difference of ApoE genotype frequency between control and MCI subjects. The inconsistency of our study with other published studies may be attributed to the specifically studied population. In the current study, all the participants were non-demented community-dwellers, while, in other studies, the participants were clinically diagnosed cognitive impaired subjects or $\mathrm{AD}$ patients $(38,39)$.

Studies have indicated that an increase of serum cholesterol concentration is a potential risk factor for cognitive decline and 
TABLE 6 | Cognition according to serum cortisol level and ApoE genotype.

\begin{tabular}{|c|c|c|c|c|c|c|}
\hline \multirow[t]{2}{*}{ Cognition } & \multirow[t]{2}{*}{ ApoE genotype } & \multicolumn{4}{|c|}{ Cortisol ( $\mu \mathrm{g} / \mathrm{ml})$} & \multirow[t]{2}{*}{$P$-value } \\
\hline & & Q1 $(n=118)$ & Q2 $(n=118)$ & Q3 $(n=118)$ & Q4 (n=118) & \\
\hline \multirow[t]{3}{*}{ MoCA score } & $\mathrm{E} 2(n=79)$ & $23.29(20.84,25.74)$ & $23.67(21.07,26.28)$ & $22.87(20.81,24.92)$ & $21.51(18.61,24.41)$ & 0.733 \\
\hline & E3 $(n=318)$ & $22.95(21.79,24.11)$ & $24.14(22.91,25.38)$ & $24.21(23.02,25.40)^{b}$ & $24.19(23.08,25.31)^{b}$ & \\
\hline & E4 $(n=75)$ & $23.36(19.82,24.90)$ & $22.26(20.36,24.17)$ & $22.63(19.84,25.42)$ & $20.86(18.16,23.57)$ & \\
\hline \multirow[t]{3}{*}{ Visual-spatial and executive } & E2 $(n=79)$ & $3.55(3.00,4.11)$ & $3.49(2.90,4.08)$ & $3.58(3.11,4.04)$ & $2.94(2.29,3.60)$ & 0.448 \\
\hline & E3 $(n=318)$ & 3.57 (3.30, 3.83) & $3.80(3.52,4.08)$ & $3.52(3.25,3.79)$ & $3.83(3.58,4.08)$ & \\
\hline & $\mathrm{E} 4(n=75)$ & $3.44(2.86,4.01)$ & $3.48(3.05,3.91)$ & $3.46(2.83,4.09)$ & $3.25(2.64,3.86)$ & \\
\hline \multirow[t]{3}{*}{ Naming } & E2 $(n=79)$ & $3.00(2.74,3.25)$ & $2.96(2.68,3.23)$ & $2.73(2.52,2.95)$ & $2.73(2.43,3.03)$ & 0.462 \\
\hline & E3 $(n=318)$ & $2.86(2.74,2.98)$ & $2.89(2.77,3.02)^{a}$ & $2.89(2.77,3.01)$ & $2.96(2.84,3.08)^{a}$ & \\
\hline & $\mathrm{E} 4(n=75)$ & $2.76(2.50,3.03)$ & $2.60(2.40,2.80)$ & $2.67(2.38,2.96)$ & $2.58(2.29,2.86)$ & \\
\hline \multirow[t]{3}{*}{ Attention } & $\mathrm{E} 2(n=79)$ & $4.92(4.31,5.54)$ & $5.21(4.56,5.86)$ & $5.24(4.72,5.75)$ & $4.97(4.25,5.70)$ & 0.711 \\
\hline & E3 $(n=318)$ & $4.88(4.59,5.17)$ & $5.19(4.88,5.50)$ & $5.25(4.96,5.55)$ & $5.33(5.05,5.61)^{\mathrm{a}}$ & \\
\hline & $\mathrm{E} 4(n=75)$ & $4.88(4.24,5.52)$ & $4.97(4.49,5.44)$ & $5.07(4.37,5.77)$ & $4.43(3.76,5.11)$ & \\
\hline \multirow[t]{3}{*}{ Language } & $\mathrm{E} 2(n=79)$ & $2.13(1.75,2.51)$ & $2.25(1.84,2.65)$ & $1.78(1.46,2.10)^{\star \star}$ & $1.61(1.16,2.07)^{\star \star}$ & 0.039 \\
\hline & E3 $(n=318)$ & $2.00(1.82,2.18)$ & $2.15(1.96,2.34)^{a}$ & $2.20(2.02,2.39)^{a, b}$ & $2.13(1.96,2.30)^{b}$ & \\
\hline & $\mathrm{E} 4(n=75)$ & $2.26(1.86,2.65)$ & $1.82(1.53,2.12)$ & $1.66(1.23,2.10)$ & $1.81(1.39,2.23)$ & \\
\hline \multirow[t]{3}{*}{ Abstraction } & $\mathrm{E} 2(n=79)$ & $1.22(0.84,1.62)$ & $1.60(1.19,2.00)^{\star}$ & $1.35(1.03,1.67)^{\star}$ & $1.37(0.92,1.82)^{\star}$ & 0.969 \\
\hline & E3 $(n=318)$ & $1.45(1.27,1.63)$ & $1.56(1.37,1.75)$ & $1.56(1.38,1.75)$ & $1.60(1.42,1.77)$ & \\
\hline & $\mathrm{E} 4(n=75)$ & $1.36(0.97,1.75)$ & $1.38(1.09,1.68)$ & $1.31(0.88,1.74)$ & $1.43(1.01,1.85)$ & \\
\hline \multirow[t]{3}{*}{ Memory and delayed recall } & $\mathrm{E} 2(n=79)$ & $2.75(2.10,3.40)$ & $2.52(1.82,3.21)$ & $2.45(1.91,3.00)$ & $2.36(1.59,3.13)$ & 0.769 \\
\hline & E3 $(n=318)$ & $2.62(2.31,2.93)$ & $2.81(2.48,3.14)$ & $3.03(2.71,3.34)^{b}$ & $2.48(2.19,2.78)^{\star},{ }^{\star \star}$ & \\
\hline & $\mathrm{E} 4(n=75)$ & $2.13(1.45,2.81)$ & $2.73(2.23,3.24)$ & $2.79(2.05,3.54)$ & $2.26(1.54,2.98)$ & \\
\hline \multirow[t]{3}{*}{ Orientation } & E2 $(n=79)$ & $5.72(5.20,6.24)$ & $5.65(5.10,6.20)$ & $5.74(5.31,6.18)$ & $5.53(4.91,6.14)$ & 0.676 \\
\hline & E3 $(n=318)$ & $5.59(5.35,5.84)$ & $5.74(5.48,6.00)$ & $5.76(5.51,6.01)$ & $5.86(5.63,6.10)^{\mathrm{a}}$ & \\
\hline & E4 $(n=75)$ & $5.52(4.99,6.06)$ & $5.28(4.88,5.68)$ & $5.67(5.08,6.26)$ & $5.11(4.54,5.68)$ & \\
\hline
\end{tabular}

Data were expressed as mean (95\% Cl). General linear model (GLM) was used for data analysis. Possible confounding factors including gender, age, BMI, smoking, physical activity, and education were adjusted. $P<0.05$ was considered to be statistically significant.

${ }^{*}$ Comparing with $Q 1$ group, $P<0.05$.

${ }^{* *}$ Comparing with Q2 group, $P<0.05$.

${ }^{a}$ Comparing with E4 carriers, $P<0.05$.

${ }^{b}$ Comparing with E2 carriers, $P<0.05$.

ApoE, apolipoprotein E; MoCA, Montreal Cognitive Assessment; Q, quartile.

dementia (40-43). In this current study, MCI subjects demonstrated relatively higher serum TC levels than normal subjects. However, a 7-year follow-up study (42) and the Framingham cohort study (44) did not observe any relationship between serum TC levels and the risk of AD (45). Siest and Merched also reported that $\mathrm{AD}$ patients have lower serum TC and HDL-C concentration than controls $(46,47)$. An inverse relationship between serum TC levels and the risk of dementia observed in an aged population (70 years old and above) (48) indicate that age dependent changes affecting serum TC levels and the time for serum TC measurements in different studies might contribute to these conflicting results.

After grouping the subjects according to ApoE genotypes, we found that serum lipid profile was ApoE genotype associated. ApoE genotype-dependent cognitive performance was also observed, demonstrated by the diminished naming ability in ApoE4 carriers compared to ApoE2 and ApoE3 carriers. As a receptor-binding ligand, ApoE is mainly known to be responsible for the transportation and metabolism of very LDL and HDL, and thus involved in the regulation of serum lipid profile (49). Furthermore, ApoE genetic variation-associated lipid metabolism disorder was suggested to be involved in the pathological progression of $\mathrm{AD}$ (50). Although the gene-dose effect of ApoE $\varepsilon 4$ allele on the risk of both cognitive decline and $\mathrm{AD}$ has been indicated by previous studies (51-53), to date, the ApoE $\varepsilon 4$ allele is solely suggested as a risk factor for $\mathrm{AD}$ rather than its cause $(54,55)$. All these results indicate that the correlation between ApoE genotype and cognitive performance in the elderly population might be potentially attributed to the concurring disturbance of lipid metabolism.

Increasing laboratory- and animal-based studies undoubtedly prove the neuroprotective effect(s) of estrogen. Lebrun's population-based study also demonstrated a negative correlation between circulating estrogen content with the risk of MCI (56). However, contradictory outcomes were concluded from clinical use of estrogen for the treatment and prevention of AD. Yaffe's study indicated that a high circulating estrogen levels predict a high risk of cognitive decline (57). Also, higher midlife circulating estrogen in male subjects predicted a smaller left and right brain occipital lobe volumes in late life (58). A cohort study found that higher circulating estrogen concentrations corresponded with a decline in verbal fluency in postmenopausal women (59). In the current study, we found a decreased tendency of memory and delayed recall ability accompanied with the increase of serum 
TABLE 7 | Serum steroid, ApoE genotype, and the risk of $\mathrm{MCl}$.

\begin{tabular}{|c|c|c|c|c|c|c|}
\hline Item & $B$ & SE & Wald & OR & $95 \% \mathrm{Cl}$ & $P$-value \\
\hline \multicolumn{7}{|c|}{ Independent effects of estradiol } \\
\hline Q1 (reference) & & - & 9.256 & 1.000 & - & 0.026 \\
\hline Q2 & 0.139 & 0.305 & 0.208 & 1.149 & $0.633,2.087$ & 0.648 \\
\hline Q3 & 0.672 & 0.291 & 5.328 & 1.958 & $1.107,3.466$ & 0.021 \\
\hline Q4 & 0.695 & 0.219 & 5.735 & 2.004 & $1.135,3.540$ & 0.017 \\
\hline \multicolumn{7}{|c|}{ Independent effects of cortisol } \\
\hline Q1 (reference) & - & - & 2.228 & 1.000 & - & 0.526 \\
\hline Q2 & -0.211 & 0.282 & 0.056 & 0.810 & $0.465,1.408$ & 0.454 \\
\hline Q3 & -0.339 & 0.287 & 1.396 & 0.713 & $0.406,1.250$ & 0.237 \\
\hline Q4 & 0.025 & 0.276 & 0.008 & 1.026 & $0.597,1.762$ & 0.927 \\
\hline \multicolumn{7}{|c|}{ Independent effects of ApoE genotype } \\
\hline E3 (reference) & - & - & 4.543 & 1.000 & - & 0.103 \\
\hline E2 & 0.608 & 0.315 & 3.721 & 1.838 & $0.990,3.410$ & 0.054 \\
\hline E4 & 0.377 & 0.304 & 1.543 & 1.458 & $0.804,2.644$ & 0.214 \\
\hline \multicolumn{7}{|c|}{ Synergistic effects of estradiol and ApoE genotype } \\
\hline Q1 × E3 (reference) & - & - & 12.305 & 1.000 & - & 0.055 \\
\hline $\mathrm{Q} 2 \times \mathrm{E} 2$ & 0.428 & 0.459 & 0.869 & 1.534 & $0.624,3.768$ & 0.351 \\
\hline $\mathrm{Q} 2 \times \mathrm{E} 4$ & 0.071 & 0.603 & 0.014 & 1.073 & $0.329,3.502$ & 0.906 \\
\hline $\mathrm{Q} 3 \times \mathrm{E} 2$ & 1.141 & 0.569 & 4.026 & 3.131 & $1.027,9.546$ & 0.045 \\
\hline $\mathrm{Q} 3 \times \mathrm{E} 4$ & 0.900 & 0.434 & 4.304 & 2.460 & $1.051,5.758$ & 0.038 \\
\hline $\mathrm{Q} 4 \times \mathrm{E} 2$ & 1.105 & 0.500 & 4.882 & 3.019 & $1.133,8.046$ & 0.027 \\
\hline $\mathrm{Q} 4 \times \mathrm{E} 4$ & 0.294 & 0.478 & 0.379 & 1.342 & $0.526,3.423$ & 0.538 \\
\hline \multicolumn{7}{|c|}{ Synergistic effects of cortisol and ApoE genotype } \\
\hline Q1 × E3 (reference) & - & - & 7.604 & 1.000 & - & 0.269 \\
\hline $\mathrm{Q} 2 \times \mathrm{E} 2$ & -0.176 & 0.589 & 0.090 & 0.838 & $0.264,2.660$ & 0.765 \\
\hline $\mathrm{Q} 2 \times \mathrm{E} 4$ & 0.517 & 0.391 & 1.748 & 1.677 & $0.779,3.606$ & 0.186 \\
\hline $\mathrm{Q} 3 \times \mathrm{E} 2$ & 0.229 & 0.425 & 0.291 & 1.257 & $0.547,2.891$ & 0.590 \\
\hline $\mathrm{Q} 3 \times \mathrm{E} 4$ & 0.635 & 0.553 & 1.318 & 1.886 & $0.638,5.573$ & 0.251 \\
\hline $\mathrm{Q} 4 \times \mathrm{E} 2$ & 1.210 & 0.553 & 4.792 & 3.353 & $1.135,9.907$ & 0.029 \\
\hline $\mathrm{Q} 4 \times \mathrm{E} 4$ & -0.089 & 0.596 & 0.023 & 0.914 & $0.285,2.939$ & 0.881 \\
\hline
\end{tabular}

Logistic regression models were created to evaluate the independent and synergistic effects of serum steroids and/or ApoE genotype on the risk of $\mathrm{MCl}$. Confounding factors such as age, sex, BMI, education, smoking, and physical activity levels were adjusted during analysis.

$\mathrm{MCl}$, mild cognitive impairment; $\mathrm{OR}$, odds ratio; $\mathrm{Cl}$, confidence interval; $\mathrm{Q}$, quartile.

estradiol levels in the elderly. This result was in agreement with Johansson's case-control study, in which the author detected an increase of serum estrogen concentration in both male and female MCI patients (60).

Physiologic relationship between estrogen and apolipoprotein has also been well established (61). The involvement of ApoE in the metabolism of cholesterol indicates the possible interaction between ApoE genetic polymorphism with cholesterol-derived steroids in affecting cognition in the elderly population. In ApoE4 negative women, estrogen replacement therapy (ERT) could reduce the risk of $\mathrm{AD}$ by $80 \%$; but in female ApoE4 carriers, ERT could not affect their susceptibility to AD (62). These findings suggest that the mechanism(s) involved and efficacy of in vivo estrogen and/or ERT in the prevention of $\mathrm{AD}$ was $\mathrm{ApoE}$ genotype dependent. Our data further consent to the involvement of ApoE genotype in the relationship between in vivo estradiol levels and cognitive performance in aging subjects. The visual-spatial and executive function of ApoE2 carriers and naming ability of ApoE4 carriers were correlated with changes in serum estrogen concentration. Moreover, the interaction of serum estradiol and ApoE genotype on the risk of MCI in this older Chinese population was also indicated by the significantly increased risk of MCI in ApoE2 carriers with Q3 or Q4 quartile level of serum estradiol status. ApoE2 has been suggested as having a protective effect against cognitive decline and delaying the aging of brain in $\mathrm{AD}$ (63). However, the $\mathrm{AD}$ preventing effect of ApoE2 is generally observed in E2/E3 individuals or in E2 homozygous females $(64,65)$. The relationship between ApoE2 and AD-like neuropathologic features appear to be very complex. ApoE2 has also been reported to increase Alzheimer pathology (specifically neuritic plaques) in the elderly (66). Study of Swedish individuals found that ApoE2 was associated with a reduced risk of AD only in females (67). The carriage of the ApoE2 is associated with a greater risk for hyperinsulinemia and diabetes, both of which increase the risk for $\operatorname{AD}(68,69)$. The synergistic effects of estrogen and ApoE in affecting multiple pathogenic mechanisms of AD have been reported (70). Nathan et al. reported an ApoE genotype-dependency on neurite outgrowth effect with estrogen status (71). It was also found that estrogen could activate glucose metabolism system and suppress ketogenic system in ApoE 2 carriers (72). Therefore, in ApoE2 carriers, high estradiol status would result in higher glucose metabolism and suppression of the ketogenic system in brain, and put brain at metabolic risk (73). All these data indicated a complex interaction between ApoE genotype, estradiol and brain function. Although, up to date, only few studies have explored the interaction of ApoE2 with sex steroids in affecting cognition, outcomes from ours and others' studies demonstrate an ApoE genotype dependent association of in vivo estrogen status and cognitive function. The association between ApoE2 and estradiol remains yet to be fully clarified.

In fact, less evidence has been contributed to the association of cortisol levels with cognition. It has been proposed that memory performance could be modulated by circulating cortisol in an "inverted-U shape" way (74-76). In contrast to these findings, several studies have shown that $\mathrm{AD}$ patients have higher basal circulating cortisol concentration than healthy control subjects (77). Chronically elevated circulating cortisol level initiated by the dysregulation of the HPA axis was often associated with accelerated declivity in cognitive functioning of the elderly (78-80). Lind et al. study observed an increased awakening salivary cortisol levels in MCI subjects compared to elderly controls (81). In the current study, we did not observe serum cortisol dependent differences in cognitive performance in these elderly subjects. Likewise, logistic analysis results did not also indicate any significance between serum cortisol with the risk of MCI in the elderly Chinese subjects. However, after taking ApoE genotype into account, it is interesting to observe that ApoE2 and ApoE4 carriers with relatively higher serum cortisol levels demonstrated lower language ability; and the genotype-cortisol interaction in affecting language ability was significant. Further logistic analysis also found an interaction of ApoE2 genotype and higher serum cortisol with the risk of MCI. More recently, a dose-dependent effect of ApoE4 and ApoE2 genotypes on behavioral symptoms in patients with frontotemporal dementia was indicated by a prospective study (82). Other studies have also reported a relationship between cortisol status, changes in regional brain 
volumes and cognitive function. For example, high circulating cortisol status was found to be correlating with brain atrophy especially in bilateral hippocampal and cerebellar gray matter (83). Hydrocortisone challenge was also found to dramatically decrease hippocampal volume in healthy subjects (84). Together with our present results, all these data are in line with the hypothesis that ApoE genotype and circulating cortisol potentially contribute to cognitive performance. The higher circulating cortisol in ApoE2 or E4 carriers may indicate a greater risk for cognitive decline.

Several limitations need to be considered in this present study. All the participants were community residents from the Beijing city. This implies that the extrapolation of our conclusions with regard to other populations should be carefully noted. Furthermore, the cross-sectional design of the present study renders weakness. We could not follow-up on the prandial changes of sex steroids in vivo. Finally, although, all factors known to be associated with cognition or serum parameter levels were adjusted, some other unidentified factors may have influence on the results and consequently on the overall ApoE genotypedependent cognitive outcomes.

\section{CONCLUSION}

The current study explored the association between serum steroids and cognitive function in non-demented older Chinese subjects with different ApoE genotypes. Our data indicate an association of circulating steroid hormone with cognition. Also the relationship between steroid hormones and cognitive performance in nondemented older Chinese subjects was ApoE-genotype associated.

\section{REFERENCES}

1. Jack CR Jr, Petersen RC, Xu Y, O’Brien PC, Smith GE, Ivnik RJ, et al. Rates of hippocampal atrophy correlate with change in clinical status in aging and AD. Neurology (2000) 55:484-9. doi:10.1212/WNL.55.4.484

2. Panza F, D'Introno A, Colacicco AM, Capurso C, Del Parigi A, Caselli RJ, et al. Current epidemiology of mild cognitive impairment and other predementia syndromes. Am J Geriatr Psychiatry (2005) 13:633-44. doi:10.1097/ 00019442-200508000-00002

3. Jaffe RB. The Menopause and Perimenopausal Period. 3rd ed. Philadelphia: Saunders (1991). p. 389-408.

4. Maeda K, Tanimoto K, Terada T, Shintani T, Kakigi T. Elevated urinary free cortisol in patients with dementia. Neurobiol Aging (1991) 12:161-3. doi:10.1016/0197-4580(91)90055-O

5. Swanwick GR, Coen RF, Walsh JB, Coakley D, Lawlor BA. The predictive value of hypothalamic-pituitary-adrenal axis dysfunction in Alzheimer's disease. Biol Psychiatry (1996) 39:976-8. doi:10.1016/0006-3223(95)00590-0

6. Swanwick GR, Kirby M, Bruce I, Buggy F, Coen RF, Coakley D, et al. Hypothalamic-pituitary-adrenal axis dysfunction in Alzheimer's disease: lack of association between longitudinal and cross-sectional findings. Am J Psychiatry (1998) 155:286-9.

7. Hampson E, Duff-Canning SJ. Salivary cortisol and explicit memory in postmenopausal women using hormone replacement therapy. Psychoneuroendocrinology (2016) 64:99-107. doi:10.1016/j.psyneuen.2015.11.009

8. Lupien SJ, de Leon M, de Santi S, Convit A, Tarshish C, Nair NP, et al. Cortisol levels during human aging predict hippocampal atrophy and memory deficits. Nat Neurosci (1998) 1:69-73. doi:10.1038/1149

9. McEwen BS, Stellar E. Stress and the individual. Mechanisms leading to disease. Arch Intern Med (1993) 153:2093-101. doi:10.1001/archinte.1993. 00410180039004
ApoE2 carriers with higher serum steroids might be predictive of having an increased risk of developing MCI.

\section{ETHICS STATEMENT}

This study was carried out in accordance with the recommendations of "The Medical Ethics Committee of Capital Medical University (No. 2012SY23)" with written informed consent from all subjects. All subjects gave written informed consent in accordance with the Declaration of Helsinki. The protocol was approved by the "The Medical Ethics Committee of Capital Medical University."

\section{AUTHOR CONTRIBUTIONS}

LY gave contribution to the design of the work and the writing of the article. $\mathrm{XH}, \mathrm{JZ}$, and TL did the contributed to the biomarkers measurements. SD, HZ, YZ, and JZ contributed to the cognitive function test. NVHL, SD, and LY contributed to the analysis and interpretation of data. LY, XH, TL, SD, HZ, JZ, YZ, and NVHL gave the approval of the final version to be published.

\section{ACKNOWLEDGMENTS}

The authors thank all participants for their participation in the present study. This study was supported by the grants from the National Natural Science Foundation of China (nos. 81673148; 81273071) and the 2015 Chinese Nutrition Society (CNS) Nutrition Research Foundation, DSM Research Fund (no. CNS2015070B).

10. Fuller S, Tan R, Martins R. Androgens in the etiology of Alzheimer's disease in aging men and possible therapeutic interventions. J Alzheimer Dis (2007) 12:129-42. doi:10.3233/JAD-2007-12202

11. Luine V. Sex steroids and cognitive function. J Neuroendocrinol (2008) 20:866-72. doi:10.1111/j.1365-2826.2008.01710.x

12. Karlamangla AS, Singer BH, Chodosh J, McEwen BS, Seeman TE. Urinary cortisol excretion as a predictor of incident cognitive impairment. Neurobiol Aging (2005) 26:80-4. doi:10.1016/j.neurobiolaging.2005.09.037

13. Umeda-Kameyama Y, Akishita M. Age and sex: risk factors for dementia. Brain Nerve (2016) 68:713-8. doi:10.11477/mf.1416200499

14. Huo DS, Sun JF, Zhang B, Yan XS, Wang H, Jia JX, et al. Protective effects of testosterone on cognitive dysfunction in Alzheimer's disease model rats induced by oligomeric beta amyloid peptide 1-42. J Toxicol Environ Health A (2016) 79:856-63. doi:10.1080/15287394.2016.1193114

15. Li R, Singh M. Sex differences in cognitive impairment and Alzheimer's disease. Front Neuroendocrinol (2014) 35:385-403. doi:10.1016/j.yfrne.2014.01.002

16. Rosario ER, Chang L, Head EH, Stanczyk FZ, Pike CJ. Brain levels of sex steroid hormones in men and women during normal aging and in Alzheimer's disease. Neurobiol Aging (2011) 32:604-13. doi:10.1016/j.neurobiolaging. 2009.04.008

17. Yue X, Lu M, Lancaster T, Cao P, Honda SI, Staufenbiel M, et al. Brain estrogen deficiency accelerates Ab plaque formation in an Alzheimer's disease animal model. Proc Natl Acad Sci U S A (2005) 102:19198-203. doi:10.1073/ pnas.0505203102

18. Carroll JC, Rosario ER, Kreimer S, Villamagna A, Gentzschein E, Stanczyk FZ, et al. Sex differences in b-amyloid accumulation in 3xTg-AD mice: role of neonatal sex steroid hormone exposure. Brain Res (2010) 1366:233-45. doi:10.1016/j.brainres.2010.10.009

19. Hirata-Fukae C, Li HF, Hoe HS, Gray AJ, Minami SS, Hamada K, et al. Females exhibit more extensive amyloid, but not tau, pathology in an 
Alzheimer transgenic model. Brain Res (2008) 1216 IS:92-103. doi:10.1016/j. brainres.2008.03.079

20. Kaufman J, Vermeulen A. The decline of androgen levels in elderly men and its clinical and therapeutic implications. Endocr Rev (2005) 26:833-76. doi:10.1210/er.2004-0013

21. Panza F, D'Introno A, Colacicco AM, Basile AM, Capurso C, Kehoe PG, et al. Vascular risk and genetics of sporadic late-onset Alzheimer's disease. J Neural Transm (2004) 111:69-89. doi:10.1007/s00702-003-0071-1

22. Heffernan AL, Chidgey C, Peng P, Masters CL, Roberts BR. The neurobiology and age-related prevalence of the $\varepsilon 4$ allele of apolipoprotein $\mathrm{E}$ in Alzheimer's disease cohorts. J Mol Neurosci (2016) 60:316-24. doi:10.1007/ s12031-016-0804-x

23. Struble RG, Nathan BP, Cady C, Cheng X, McAsey M. Estradiol regulation of astroglia and apolipoprotein E: an important role in neuronal regeneration. Exp Gerontol (2007) 42:54-63. doi:10.1016/j.exger.2006.05.013

24. Thornton V, Warden D, Talbot C, Mastana SS, Bandelow S, Hogervorst E. Modification of estrogen's association with Alzheimer's disease risk by genetic polymorphisms. Brain Res (2011) 1379:213-23. doi:10.1016/j.brainres. 2010.12.074

25. Bowen RL, Gregory CW. Sex hormones and ApoE4: beyond steroids. J Alzheimers Dis (2004) 6:229-30. doi:10.3233/JAD-2004-6303

26. Peskind ER, Wilkinson CW, Petrie EC, Schellenberg GD, Raskind MA. Increased CSF cortisol in AD is a function of APOE genotype. Neurology (2001) 56:1094-8. doi:10.1212/WNL.56.8.1094

27. Cai C, Xiao R, Van Halm-Lutterodt N, Zhen J, Huang X, Xu Y, et al. Association of MTHFR, SLC19A1 genetic polymorphism, serum folate, vitamin $\mathrm{B}(12)$ and Hcy status with cognitive functions in Chinese adults. Nutrients (2016) 8:E665. doi:10.3390/nu8100665

28. Dong L, Xiao R, Cai C, Xu Z, Wang S, Pan L, et al. Diet, lifestyle and cognitive function in old Chinese adults. Arch Gerontol Geriatr (2016) 63:36-42. doi:10.1016/j.archger.2015.12.003

29. Friedewald WT, Levy RI, Fredrickson DS. Estimation of the concentration of low-density lipoprotein cholesterol in serum, without use of the preparative ultracentrifuge. Clin Chem (1997) 18:499-502.

30. Dowsett M, Goss PE, Powles TJ, Hutchinson G, Brodie AM, Jeffcoate SL, et al. Use of aromatase inhibitor 4-hydroxyandrostenedione in postmenopausal breast cancer: optimization of therapeutic dose and route. Cancer Res (1987) 135:1220-30.

31. Hixson JE, Vernier DT. Restriction isotyping of human apolipoprotein e by gene amplification and cleavage with hhai. J Lipid Res (1990) 31:545-8.

32. Nasreddine ZS, Phillips NA, Bedirian V, Charbonneau S, Whitehead V, Collin I, et al. The Montreal Cognitive Assessment, MoCA: A brief screening tool for mild cognitive impairment. J Am Geriatr Soc (2005) 53:695-9. doi:10.1111/j.1532-5415.2005.53221.x

33. Luis CA, Keegan AP, Mullan M. Cross validation of the Montreal Cognitive Assessment in community dwelling older adults residing in the southeastern US. Int J Geriatr Psychiatry (2009) 24:197-201. doi:10.1002/gps.2101

34. Lu J, Li D, Li F, Zhou A, Wang F, Zuo X, et al. Montreal Cognitive Assessment in detecting cognitive impairment in Chinese elderly individuals: a populationbased study. JGeriatr Psychiatry Neurol (2011) 24:184-90. doi:10.1177/ 0891988711422528

35. Querfurth HW, LaFerla FM. Mechanisms of disease. Alzheimer's disease. $N$ Engl J Med (2010) 362:329-44. doi:10.1056/NEJMra0909142

36. Solfrizzi V, Panza F, Colacicco AM, D'Introno A, Capurso C, Torres F, et al. Vascular risk factors, incidence of MCI, and rates of progression to dementia. Neurology (2004) 63:1882-91. doi:10.1212/01.WNL.0000144281.38555.E3

37. Blumenthal JA, Babyak MA, Doraiswamy PM, Watkins L, Hoffman BM, Barbour KA, et al. Exercise and pharmacotherapy in the treatment of major depressive disorder. Psychosom Med (2007) 69:587-96. doi:10.1097/ PSY.0b013e318148c19a

38. Whitehair DC, Sherzai A, Emond J, Raman R, Aisen PS, Petersen RC, et al. Alzheimer's Disease Cooperative Study. Influence of apolipoprotein E varepsilon 4 on rates of cognitive and functional decline in mild cognitive impairment. Alzheimers Dement (2010) 6:412-9. doi:10.1016/j.jalz.2009.12.003

39. Waring JF, Tang Q, Robieson WZ, King DP, Das U, Dubow J, et al. APOE- $\varepsilon 4$ carrier status and donepezil response in patients with Alzheimer's disease. J Alzheimers Dis (2015) 47:137-48. doi:10.3233/JAD-142589

40. Kuusisto J, Koivisto K, Mykkänen L, Helkala EL, Vanhanen M, Hänninen T, et al. Association between features of the insulin resistance syndrome and
Alzheimer's disease independently of apolipoprotein E4 phenotype: cross sectional population based study. BMJ (1997) 315:1045-9. doi:10.1136/ bmj.315.7115.1045

41. Notkola IL, Sulkava R, Pekkanen J, Erkinjuntti T, Ehnholm C, Kivinen P. Serum total cholesterol, apolipoprotein E epsilon 4 allele, and Alzheimer's disease. Neuroepidemiology (1998) 17:14-20. doi:10.1159/000026149

42. Reitz C, Tang MX, Luchsinger J, Mayeux R. Relation of plasma lipids to Alzheimer disease and vascular dementia. Arch Neurol (2004) 61:705-14. doi:10.1001/archneur.61.5.705

43. Bonarek M, Barberger-Gateau P, Letenneur L, Deschamps V, Iron A, Dubroca $\mathrm{B}$, et al. Relationships between cholesterol, apolipoprotein $\mathrm{E}$ polymorphism and dementia: a cross-sectional analysis from the PAQUID study. Neuroepidemiology (2000) 19:141-8. doi:10.1159/000026249

44. Fujishima M, Kiyohara Y. Incidence and risk factors of dementia in a defined elderly Japanese population: the Hisayama study. Ann N Y Acad Sci (2002) 977:1-8. doi:10.1111/j.1749-6632.2002.tb04793.x

45. Tan ZS, Seshadri S, Beiser A, Wilson PW, Kiel DP, Tocco M, et al. Plasma total cholesterol level as a risk factor for Alzheimer disease: the Framingham Study. Arch Intern Med (2003) 163:1053-7. doi:10.1001/archinte.163.9.1053

46. Siest G, Bertrand P, Qin B, Herbeth B, Serot JM, Masana L, et al. Apolipoprotein E polymorphism and serum concentration in Alzheimer's disease in nine European centres: the ApoEurope study. ApoEurope group. Clin Chem Lab Med (2000) 38:721-30. doi:10.1515/CCLM.2000.102

47. Merched A, Xia Y, Visvikis S, Serot JM, Siest G. Decreased high-density lipoprotein cholesterol and serum apolipoprotein AI concentrations are highly correlated with the severity of Alzheimer's disease. Neurobiol Aging (2000) 21:27-30. doi:10.1016/S0197-4580(99)00103-7

48. Mielke MM, Zandi PP, Sjögren M, Gustafson D, Ostling S, Steen B, et al. High total cholesterol levels in late life associated with a reduced risk of dementia. Neurology (2005) 64:1689-95. doi:10.1212/01.WNL.0000161870.78572.A5

49. Davignon J, Cohn JS, Mabile L, Bernier L. Apolipoprotein E and atherosclerosis: insight from animal and human studies. Clinica Chimica Acta (1999) 286:115-43. doi:10.1016/S0009-8981(99)00097-2

50. Jarvik GP, Wijsman EM, Kukull WA, Schellenberg GD, Yu C, Larson EB. Interactions of apolipoprotein E genotype, total cholesterol level, age, and sex in prediction of Alzheimer's disease: a case-control study. Neurology (1995) 45:1092-6. doi:10.1212/WNL.45.6.1092

51. Corder EH, Saunders AM, Strittmatter WJ, Schmechel DE, Gaskell PC, Small GW, et al. Gene dose of apolipoprotein E type 4 allele and the risk of Alzheimer's disease in late onset families. Science (1993) 261:921-3. doi:10.1126/science. 8346443

52. Kamboh MI. Apolipoprotein E polymorphism and susceptibility to Alzheimer's disease. Hum Biol (1995) 67:195-215.

53. Strittmatter WJ, Weisgraber KH, Huang DY, Dong LM, Salvesen GS, PericakVance M, et al. Binding of human apolipoprotein $\mathrm{E}$ to synthetic amyloid beta peptide: isoformspecific effects and implications for late-onset Alzheimer disease. Proc Natl Acad Sci U S A (1993) 90:8098-102. doi:10.1073/pnas.90.17.8098

54. Davignon J, Roederer G. Phenotype of apolipoprotein E, hyperlipidemia and atherosclerosis. Union Med Can (1988) 117:56-61.

55. American College of Medical Genetics. American Society of Human Genetics Working Group on ApoE and Alzheimer Disease. JAMA (1995) 274:1627-9.

56. Lebrun CE, van der Schouw YT, de Jong FH, Pols HA, Grobbee DE, Lamberts SW. Endogenous oestrogens are related to cognition in healthy elderly women. Clin Endocrinol (2005) 63:50-5. doi:10.1111/j.1365-2265.2005.02297.x

57. Yaffe K, Grady D, Pressman A, Cummings S. Serum estrogen levels, cognitive performance, and risk of cognitive decline in older community women. J Am Geriatr Soc (1998) 46:816-21. doi:10.1111/j.1532-5415.1998.tb02713.x

58. Lessov-Schlaggar CN, Reed T, Swan GE, Krasnow RE, DeCarli C, Marcus R, et al. Association of sex steroid hormones with brain morphology and cognition in healthy elderly men. Neurology (2005) 65:1591-6. doi:10.1212/01. wnl.0000184512.08249.48

59. Laughlin GA, Kritz-Silverstein D, Elizabeth Barrett-Connor E. Higher endogenous estrogens predict four year decline in verbal fluency in postmenopausal women: the Rancho Bernardo study. Clin Endocrinol (2010) 72:99-106. doi:10.1111/j.1365-2265.2009.03599.x

60. Johansson P, Johansson JO, Labrie F, Mattsson N, Hansson O, Blennow K, et al. Mild dementia is associated with increased adrenal secretion of cortisol and precursor sex steroids in women. Clin Endocrinol (Oxf) (2011) 75:301-8. doi:10.1111/j.1365-2265.2011.04082.x 
61. Depypere H, Vierin A, Weyers S, Sieben A. Alzheimer's disease, apolipoprotein E and hormone replacement therapy. Maturitas (2016) 94:98-105. doi:10.1016/j.maturitas.2016.09.009

62. Rippon GA, Tang MX, Lee JH, Lantigua R, Medrano M, Mayeux R. Familial Alzheimer disease in Latinos: interaction between APOE, stroke, and estrogen replacement. Neurology (2006) 66:35-40. doi:10.1212/01. wnl.0000191300.38571.3e

63. Corder EH, Saunders AM, Risch NJ, Strittmatter WJ, Schmechel DE, Gaskell PC Jr, et al. Protective effect of apolipoprotein E type 2 allele for late onset Alzheimer disease. Nat Genet (1994) 7:180-4. doi:10.1038/ng0694-180

64. Sheffler J, Moxley J, Sachs-Ericsson N. Stress, race, and APOE: understanding the interplay of risk factors for changes in cognitive functioning. Aging Ment Health (2014) 18:784-91. doi:10.1080/13607863.2014.880403

65. Yao J, Brinton RD. Estrogen regulation of mitochondrial bioenergetics: implications for prevention of Alzheimer's disease. Adv Pharmacol (2012) 64:327-71. doi:10.1016/B978-0-12-394816-8.00010-6

66. Berlau DJ, Corrada MM, Head E, Kawas CH. APOE epsilon2 is associated with intact cognition but increased Alzheimer pathology in the oldest old. Neurology (2009) 72:829-34. doi:10.1212/01.wnl.0000343853.00346.a4

67. Qiu C, Kivipelto M, Agüero-Torres H, Winblad B, Fratiglioni L. Risk and protective effects of the APOE gene towards Alzheimer's disease in the Kungsholmen project: variation by age and sex. J Neurol Neurosurg Psychiatry (2004) 75:828-33. doi:10.1136/jnnp.2003.021493

68. Kuhel DG, Konaniah ES, Basford JE, McVey C, Goodin CT, Chatterjee TK, et al. Apolipoprotein E2 accentuates postprandial inflammation and diet-induced obesity to promote hyperinsulinemia in mice. Diabetes (2013) 62:382-91. doi:10.2337/db12-0390

69. Satirapoj B, Supasyndh O, Dispan R, Punpanich D, Tribanyatkul S, Choovichian P. Apolipoprotein E genetic polymorphisms and the development of nephropathy in type 2 diabetes. J Med Assoc Thai (2013) 96:1119-26.

70. Xing Y, Jia JP, Ji XJ, Tian T. Estrogen associated gene polymorphisms and their interactions in the progress of Alzheimer's disease. Prog Neurobiol (2013) 111:53-74. doi:10.1016/j.pneurobio.2013.09.006

71. Nathan BP, Barsukova AG, Shen F, McAsey M, Struble RG. Estrogen facilitates neurite extension via apolipoprotein $\mathrm{E}$ in cultured adult mouse cortical neurons. Endocrinology (2004) 145:3065-73. doi:10.1210/en.2003-1707

72. Klosinski LP, Yao J, Yin F, Fonteh AN, Harrington MG, Christensen TA, et al. White matter lipids as a ketogenic fuel supply in aging female brain: implications for Alzheimer's disease. EBioMedicine (2015) 2:1888-904. doi:10.1016/j. ebiom.2015.11.002

73. Riedel BC, Thompson PM, Brinton RD. Age, APOE and sex: triad of risk of Alzheimer's disease. J Steroid Biochem Mol Biol (2016) 160:134-47. doi:10.1016/j.jsbmb.2016.03.012

74. Diamond DM, Bennett MC, Fleshner M, Rose GM. Inverted-U relationship between the level of peripheral corticosterone and the magnitude of hippocampal primed burst potentiation. Hippocampus (1992) 2:421-30. doi:10.1002/hipo.450020409
75. Roozendaal B. Glucocorticoids and the regulation of memory consolidation. Psychoneuroendocrinology (2000) 25:213-38. doi:10.1016/ S0306-4530(99)00058-X

76. Lupien SJ, McEwen BS. The acute effects of corticosteroids on cognition: integration of animal and human model studies. Brain Res Rev (1997) 24:1-27. doi:10.1016/S0165-0173(97)00004-0

77. Hartmann A, Veldhuis JD, Deuschle M, Standhardt H, Heuser I. Twentyfour hour cortisol release profiles in patients with Alzheimer's and Parkinson's disease compared to normal controls: ultradian secretory pulsatility and diurnal variation. Neurobiol Aging (1997) 18:285-9. doi:10.1016/ S0197-4580(97)80309-0

78. Lupien SJ, Maheu F, Tu M, Fiocco A, Schramek TE. The effects of stress and stress hormones on human cognition: implications for the field of brain and cognition. Brain Cogn (2007) 65:209-37. doi:10.1016/j.bandc.2007.02.007

79. Lupien SJ, McEwen BS, Gunnar MR, Heim C. Effects of stress throughout the lifespan on the brain, behaviour and cognition. Nat Rev Neurosci (2009) 10:434-45. doi:10.1038/nrn2639

80. Comijs HC, Gerritsen L, Penninx BW, Bremmer MA, Deeg DJ, Geerlings MI. The association between serum cortisol and cognitive decline in older persons. Am J Geriatr Psychiatry (2010) 18:42-50. doi:10.1097/JGP.0b013e3181b970ae

81. Lind K, Edman A, Nordlund A, Olsson T, Wallin A. Increased saliva cortisol awakening response in patients with mild cognitive impairment. Dement Geriatr Cogn Disord (2007) 24:389-95. doi:10.1159/000109938

82. Engelborghs S, Dermaut B, Mariën P, Symons A, Vloeberghs E, Maertens $\mathrm{K}$, et al. Dose dependent effect of APOE epsilon4 on behavioral symptoms in frontal lobe dementia. Neurobiol Aging (2006) 27:285-92. doi:10.1016/j. neurobiolaging.2005.02.005

83. Burkhardt T, Lüdecke D, Spies L, Wittmann L, Westphal M, Flitsch J. Hippocampal and cerebellar atrophy in patients with Cushing's disease. Neurosurg Focus (2015) 39:E5. doi:10.3171/2015.8.FOCUS15324

84. Brown ES, Jeon-Slaughter $\mathrm{H}, \mathrm{Lu} \mathrm{H}$, Jamadar R, Issac S, Shad M, et al. Hippocampal volume in healthy controls given 3-day stress doses of hydrocortisone. Neuropsychopharmacology (2015) 40:1216-21. doi:10.1038/ npp. 2014.307

Conflict of Interest Statement: The authors declare that the research was conducted in the absence of any commercial or financial relationships that could be construed as a potential conflict of interest.

Copyright (c) 2018 Huang, Dong, Zhen, Zhang, Lin, Zeng, Van Halm-Lutterodt and Yuan. This is an open-access article distributed under the terms of the Creative Commons Attribution License (CC BY). The use, distribution or reproduction in other forums is permitted, provided the original author(s) and the copyright owner are credited and that the original publication in this journal is cited, in accordance with accepted academic practice. No use, distribution or reproduction is permitted which does not comply with these terms. 


\section{APPENDIX}

TABLE A1 | MCl, ApoE genotype, and serum parameters according to age.

\begin{tabular}{|c|c|c|c|c|}
\hline Items & \multicolumn{3}{|c|}{ Age (years) } & $P$ value \\
\hline $\mathrm{MCl}, n(\%)$ & $56(26.0)$ & $64(31.1)$ & $24(47.1)$ & 0.017 \\
\hline E2 & $31(14.4)$ & $36(17.5)$ & $12(23.5)$ & \\
\hline E3 & $148(68.8)$ & $138(67.0)$ & $32(62.7)$ & \\
\hline E4 & $36(16.7)$ & $32(15.5)$ & $7(13.7)$ & \\
\hline $\mathrm{TC}(\mathrm{mmol} / \mathrm{l})$ & $5.34(5.19,5.49)$ & $5.14(4.98,5.29)$ & $5.39(5.09,5.70)$ & 0.117 \\
\hline $\mathrm{TG}(\mathrm{mmol} / \mathrm{l})$ & $2.19(1.97,2.41)$ & $2.09(1.86,2.32)$ & $1.97(1.52,2.42)$ & 0.635 \\
\hline $\mathrm{HDL}-\mathrm{C}(\mathrm{mmol} / \mathrm{l})$ & $1.41(1.37,1.45)$ & $1.40(1.37,1.44)$ & $1.49(1.41,1.57)$ & 0.132 \\
\hline LDL-C (mmol/l) & $3.07(2.95,3.18)$ & $2.93(2.82,3.05)$ & $3.00(2.77,3.24)$ & 0.282 \\
\hline Estradiol (pg/ml) & $19.83(18.16,21.51)$ & $19.80(18.07,21.54)$ & $20.57(17.12,24.02)$ & 0.922 \\
\hline Cortisol (ng/ml) & $208.75(201.73,215.77)$ & $211.62(204.34,218.90)$ & $211.07(196.60,225.55)$ & 0.850 \\
\hline
\end{tabular}

MCl, mild cognitive impairment; ApoE, Apolipoprotein E; TC, total cholesterol; TG, triglyceride; LDL-C, low density lipoprotein cholesterol; HDL-C, high density lipoprotein cholesterol.

Chi-square test was used for binary categorical variables difference between groups. General Linear Model method was used for the comparison of serum parameters. During the comparison of serum lipids status, confounding factors including sex, BMI, physical activity, smoking, and alcohol drinking were adjusted. During the comparison of serum estradiol and cortisol levels, confounding factors including sex, BMI, physical activity were adjusted. P value $<0.05$ was considered as significance. 